\title{
Fetal Cardiac Natriuretic Peptide Expression and Cardiovascular Hemodynamics in Endotoxin-Induced Acute Cardiac Dysfunction in Mouse
}

\author{
KAARIN MÄKIKALLIO, SAMULI ROUNIOJA, OLLI VUOLTEENAHO, JENNA PAAKKARI, MIKKO HALLMAN, AND \\ JUHA RÄSÄNEN
}

\begin{abstract}
Department of Obstetrics and Gynecology [K.M., J.R.], Department of Pediatrics and Biocenter Oulu [S.R., M.H.], Department of Physiology and Biocenter Oulu [O.V., J.P.], University of Oulu, Oulu, FIN 90014 Finland
\end{abstract}

\begin{abstract}
We hypothesized that, in acute endotoxin-induced fetal cardiac dysfunction, atrial (ANP) and B-type (BNP) natriuretic peptide mRNA expressions are increased in proportion to the severity of fetal cardiovascular compromise in mouse. To investigate in vitro the effect of endotoxin-induced inflammation on cardiac natriuretic peptide expression, fetal hearts were harvested at 15-16 d of gestation and incubated for $6 \mathrm{~h}$ with lipopolysaccharide (LPS). To examine the relationship between fetal cardiovascular compromise and cardiac natriuretic peptide expression in endotoxin-induced cardiac dysfunction in the in vivo model, fetuses received intra-amniotically $25 \mu \mathrm{L}$ LPS $(10 \mu \mathrm{g} / \mathrm{mL})$ or $25 \mu \mathrm{L}$ of $0.9 \%$ saline. Fetal Doppler ultrasonography was performed before and six hours after the injections. In in vitro cultured fetal hearts, LPS induced the production of proinflammatory cytokines without affecting the basal expressions of natriuretic peptides. In the in vivo model, Doppler ultrasonography revealed severe cardiac dysfunction after LPS injection. No significant changes in ANP or atrial BNP mRNA were found. The fetal ventricular BNP mRNA levels were about 2.6-fold in the LPS group compared with the control group. Decreased fetal cardiac outflow mean velocity, increased proportion of isovolumetric contraction time of the cardiac cycle, and increased pulsatility indices of the descending aorta and inferior vena cava were related to elevated ventricular BNP mRNA levels. Our results show that LPS did not increase the mRNA expression of natriuretic peptides in cultured fetal hearts. In contrast, fetal ventricular BNP gene expression was increased in proportion to the severity of the hemodynamic compromise in vivo. (Pediatr Res 59: 180-184, 2006)
\end{abstract}

$\mathrm{I}^{\mathrm{n}}$ n human pregnancies complicated by preterm premature rupture of membranes, fetal cardiac function seems to be altered, particularly in cases with intraamniotic infection (1). In addition, premature infants born after chorioamnionitis demonstrate hemodynamic disturbances (2). In a fetal mouse model, endotoxin from Gram-negative bacteria (LPS) in the amniotic fluid acutely increased IL- $1 \beta$ and tumor necrosis factor-alpha (TNF- $\alpha$ ) mRNA expressions in the myocardium, and the fetuses demonstrated a significant cardiovascular com-

Received April 28, 2005; accepted September 9, 2005.

Correspondence: Juha Räsänen, M.D., Department of Obstetrics and Gynecology, University of Oulu, 90220 Oulu, Finland; e-mail: juha.rasanen@oulu.fi K.M. and S.R. have equally contributed to this study.

Supported by the Academy of Finland, Maud Kuistila Research Foundation, Instrumentarium Research Foundation, the Alma and K.A. Snellman Foundation, Sigrid Juselius Foundation, and Emil Aaltonen Foundation.

DOI: 10.1203/01.pdr.0000196719.95046.19 promise (3) Presumably, the inflammatory response in the fetal myocardium combined with the increased afterload led to severe cardiac dysfunction.

ANP and BNP are secreted in response to cardiac volume and pressure overload (4). They increase salt and water excretion, enhance capillary permeability, and cause direct relaxation of vascular smooth muscle (4). In adults, ANP is mainly produced by the atria, whereas the ventricles are the main production sites of BNP. In fetuses and neonates, the ANP gene is very actively expressed in the ventricles (5).

The present study was designed to further explore the relationships between myocardial inflammation, fetal cardiovascular hemodynamics, and myocardial expression of natriuretic peptides in acute endotoxin-induced fetal cardiac dysfunction. We hypothesized that intra-amniotic LPS increases fetal cardiac natriuretic peptide gene expression in proportion to the severity of the fetal cardiovascular compromise. To test this hypothesis, an in vitro organ culture model was developed to explore the direct effect of LPS-induced inflammation on the fetal myocardial expression of natriuretic peptides. Moreover, an in vivo mouse model with intra-amniotic LPS exposure was used to examine the impact of the severity of the cardiovascular compromise on fetal cardiac natriuretic peptide expression.

\section{MATERIALS AND METHODS}

The Animal Research Committee of the University of Oulu approved the study protocol. The animals were handled in accordance with the Guide for the Care and Use of Laboratory Animals published by the US National Institutes of Health. A total of 36 timed pregnant DBA/2 mice with 154 fetuses were included in the in vitro organ culture experiments. In addition, the in vivo experimental model consisted of 12 mice with 35 fetuses. The gestational ages of the fetuses were verified by the presence of a vaginal plug (d 0 of pregnancy).

In vitro organ culture. At $15-16 \mathrm{~d}$ of gestation (term $21 \mathrm{~d}$ ), the mice were killed by cervical dislocation and the fetal hearts were carefully separated from the other tissues by using a sterile technique and transferred to a culture

Abbreviations: ANP, atrial natriuretic peptide; BNP, B-type natriuretic peptide; DAo, descending aorta; DV, ductus venosus; FHR, fetal heart rate; ICA, intracranial artery; ICT, isovolumetric contraction time; IRT, isovolumetric relaxation time; IVC, inferior vena cava; LPS, lipopolysaccharide; PI, pulsatility index; PIV, pulsatility index for veins; TVI, time velocity integral; UA, umbilical artery 
dish containing Dulbecco's modified Eagle's medium with glucose ( $4.5 \mathrm{~g} / \mathrm{L})$, glutamine $(2 \mathrm{mM})$, penicillin $(100 \mathrm{U} / \mathrm{mL})$, streptomycin $(100 \mu \mathrm{g} / \mathrm{mL})$, and fungizone $(0.25 \mu \mathrm{g} / \mathrm{mL})$. Each culture dish consisted of four to five randomly isolated fetal hearts, which were maintained in culture at $37^{\circ} \mathrm{C}$ in a humidified atmosphere of $5 \% \mathrm{CO}_{2}$ and $95 \%$ air overnight. On the following day, the viability of the hearts was verified by the presence of spontaneous contractions. The medium was changed and the tissues were randomly chosen to be incubated with LPS (Escherichia coli 055:B5; Sigma Chemical Co., St. Louis, MO) $1 \mu \mathrm{g} / \mathrm{mL}$ or vehicle for $6 \mathrm{~h}$. After the experiment, the hearts were immediately frozen in liquid nitrogen and stored at $-70^{\circ} \mathrm{C}$ until processed for mRNA analysis.

In vivo model. On the 15th or 16th gestational day, the mice were anesthetized (50 $\mu \mathrm{g}$ midazolam, $3.2 \mu \mathrm{g}$ fentanyl citrate, $100 \mu \mathrm{g}$ of fluanisone per kilogram body weight subcutaneously) for ultrasonographic examination of the fetuses and surgery. Anesthesia was monitored by loss of toe- and tailpinch reflexes. After the baseline ultrasonographic examination (see below) of the fetuses, the mice were randomized to receive either LPS or vehicle. The uterine horns were exposed through a $1.5-\mathrm{cm}$ midline abdominal incision. Either LPS or vehicle was injected into the amniotic sac of each fetus using a 30-gauge tuberculin syringe. LPS was solubilized in $0.9 \%$ sterile saline and diluted to a final concentration of $10 \mu \mathrm{g} / \mathrm{mL}$. In the LPS group (5 mice, 15 fetuses), a $25-\mu$ L LPS injection was given into the amniotic cavity. An identical intra-amniotic injection of $25 \mu \mathrm{L}$ of $0.9 \%$ saline was given in the vehicle group ( 5 mice, 14 fetuses). Our previous study with tryphan blue demonstrated that the amniotic cavity was accurately targeted without penetration of the fetal skin or placenta (3). In the control group ( 2 mice, 6 fetuses), a sham operation was performed without any intra-amniotic injections. The abdominal cavity and the abdominal wall were closed after the injections. The mice recovered from the surgery in clean individual cages in warm $\left(+25^{\circ} \mathrm{C}\right)$ microisolators. After the last ultrasonographic examination, mice were killed and the fetal hearts were collected for further analysis.

Doppler ultrasonography. Identical ultrasonographic examinations were performed before and $6 \mathrm{~h}$ after the operation by using Acuson Sequoia 512 (Mountain View, CA) with a $13 \mathrm{MHz}$ linear probe. The high-pass filter was set at its minimum. The scanning technique has been described previously $(6,7)$. After localizing the fetuses, the fetal heart was identified by color Doppler, and the sample volume of pulsed Doppler was adjusted to cover the entire heart. Different views of the fetal heart were examined to minimize the insonation angle and to optimize the measurement of the maximal blood flow velocities. The maximal inflow and outflow blood flow velocities were recorded using a sweep speed of $100 \mathrm{~mm} / \mathrm{s}$. After identification of the DAo, ICA, IVC, and DV with color Doppler on the fetal sagittal view, their blood velocity waveforms were obtained by pulsed Doppler ultrasonography. The same technique was used to record the UA blood velocity waveforms. The data were videotaped and analyzed afterward using the cardiac measurement package of the ultrasound equipment. All the ultrasonographic examinations were performed by a single investigator who was blinded to the randomization.

TVI was measured from the outflow blood velocity waveforms by planimetering the area underneath the Doppler spectrum. After obtaining the FHR, outflow mean velocity $\left(\mathrm{V}_{\text {mean }}\right)$, which is directly proportional to volume blood flow, was calculated by the formula: $\mathrm{V}_{\text {mean }}=$ FHR $\times$ TVI. The proportions of the isovolumetric relaxation (IRT\%) and contraction (ICT\%) times of the cardiac cycle were calculated. IRT was measured as the period between the end of ejection and the onset of filling, while ICT represents the period between the end of ventricular filling and the onset of ejection. In arterial circulation, the pulsatility index values $[\mathrm{PI}=$ (peak systolic velocity - end-diastolic velocity)/time-averaged $\mathrm{V}_{\max }$ over the cardiac cycle] were obtained from the DAo, ICA, and UA blood velocity waveforms. In venous circulation, the pulsatility indices for veins [PIV $=$ (peak systolic velocity velocity during atrial contraction)/time-averaged $\mathrm{V}_{\max }$ over the cardiac cycle] from the IVC and DV blood velocity waveforms were determined. Three consecutive cardiac cycles were analyzed for every measurement, and their mean values were used for further analysis.

Mean intraobserver variability in the outflow TVI measurements was $6.0 \%$ (95\% confidence interval, $4.0-8.4 \%$ ), and the corresponding variability in the PI and PIV calculations ranged from 3.6 to $6.7 \%$ (95\% confidence interval, $2.3-8.8 \%)$. In the time interval measurements, mean intraobserver variability ranged from 2.5 to $15.9 \%$ (95\% confidence interval, $2.0-21.8 \%$ ) (3).

Immediately after the second ultrasonographic examination, the mice were killed. The abdomen was opened, and the fetuses were identified according to their position at the ultrasonographic examination. The fetal hearts were harvested, and the ventricles and atria were separated under a dissection microscope using sterile technique. They were immediately frozen in liquid nitrogen and stored at $-80^{\circ} \mathrm{C}$ until the ANP and BNP mRNA analyses.

Cytokine mRNA analysis by Rnase protection assay. Total RNA was isolated using Trizol reagent (Invitrogen, Carlsbad, CA) according to the manufacturer's instructions. The mRNA levels of inducible nitric oxide synthase (iNOS), RANTES, IL- $1 \alpha$, IL- $1 \beta$, TNF- $\alpha$, IL-1 receptor 1 (IL-1R1), and macrophage inflammatory protein (MIP)-2 were analyzed by Rnase protection assay (RPA) using the Riboquant multiprobe set (BD PharMingen, San Diego, CA) as described previously (3). Constitutive GAPDH and L32 were analyzed as references. The quantity of protected RNA was determined using a PhosphorImager and associated software (Bio-Rad, Hercules, CA). Cytokine values were expressed as a ratio of the mRNA levels in the LPS versus control groups.

ANP and BNP mRNA analyses by quantitative reverse transcriptase PCR. The cDNA first strand was synthesized using M-MuLV reverse transcriptase from RNA extracted from mouse cardiac tissue. The quantitative PCR reactions were performed with an ABI 7700 Sequence Detection System using the TaqMan chemistry (Applied Biosystems, Foster City, CA). The forward and reverse primers for mouse ANP mRNA detection were GAAAAGCAAACTGAGGGCTCTG and CCTACCCCCGAAGCAGCT, respectively. The amplicon was detected using the bifunctional fluorogenic probe $5^{\prime}$-Fam ${ }^{\mathrm{TM}}-\mathrm{TCGCTGGCCCTCGGAGCCT-Tamra}{ }^{\mathrm{TM}}-3^{\prime}$. The corresponding forward primer, reverse primer, and probe for mouse BNP mRNA detection were AGGCGAGACAAGGGAGAACA, GGAGATCCATGCCGCAGA, and $5^{\prime}$-Fam ${ }^{\mathrm{TM}}$-CATCATTGCCTGGCCCATCGC-Tamra ${ }^{\mathrm{TM}}-3^{\prime}$, respectively. The results were normalized to $18 \mathrm{~S}$ RNA quantified from the same samples using the forward and reverse primers TGGTTGCAAAGCTGAAACTTAAAG and AGTCAAATTAAGCCGCAGGC, respectively. The probe for $18 \mathrm{~S}$ was $5^{\prime}$-Vic $^{\mathrm{TM}}{ }^{\mathrm{T}}$ CCTGGTGGTGCCCTTCCGTCA-Tamra ${ }^{\mathrm{TM}}-3^{\prime}$ (8).

Statistical analysis. Statistical analysis was performed by using ANOVA when comparisons were made between the three groups and the data were normally distributed. If statistically significant differences were seen, the Scheffé $\mathrm{F}$ test was used for further analysis. If the data were not normally distributed, the nonparametric Kruskal-Wallis test was used. Linear regression analysis was used to show the relationship between the examined parameters. A $p$ value of $\leq 0.05$ was considered statistically significant.

\section{RESULTS}

Cytokine and natriuretic peptide mRNA expression in in vitro cultured fetal hearts. Six hours after LPS exposure, the expressions of iNOS, RANTES, TNF- $\alpha$, IL- $1 \alpha$, IL- $1 \beta$, and MIP-2 were significantly $(p<0.05)$ increased compared with vehicle-treated fetal hearts. The expression of IL-1RI remained constitutive (Fig. 1). Fetal cardiac ANP and BNP mRNA expressions were not significantly increased $6 \mathrm{~h}$ after LPS exposure (Fig. 2).

Fetal cardiac natriuretic peptide mRNA levels in in vivo model. The atrial and ventricular ANP and atrial BNP mRNA levels did not differ significantly between the groups. On the other hand, $6 \mathrm{~h}$ after the intra-amniotic LPS injection, the

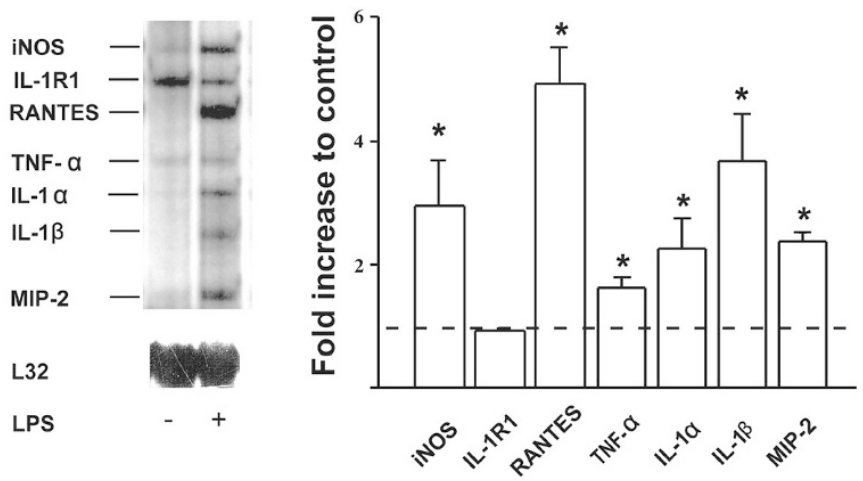

Figure 1. Expression of proinflammatory cytokines in cultured fetal hearts after LPS $(1 \mu \mathrm{g} / \mathrm{mL})$ stimulation. (A) A representative gel electrophoresis of multiple mRNA. $(B)$ The results are expressed as a fold increase compared with the control group (dotted line). Results are mean $\pm \mathrm{SE},{ }^{*} p<0.05, n=$ 5-6 culture dishes per group. 


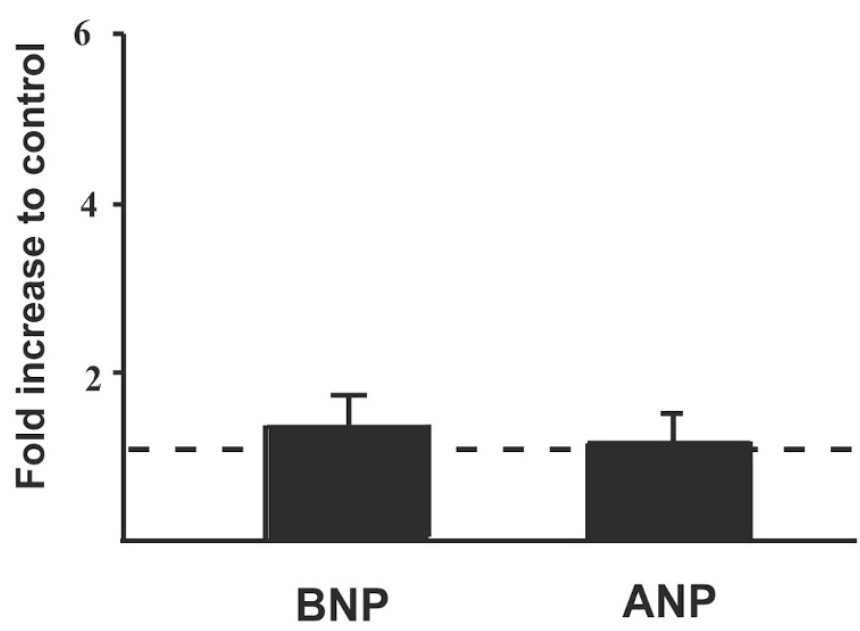

Figure 2. Natriuretic peptide expression levels in cultured fetal hearts after LPS. The data are expressed as a fold increase in mRNA levels in the LPS ( $n=10$ culture dishes) per group compared with the control group $(n=10$ culture dishes) (dotted line). Results are mean \pm SE.

expression of ventricular BNP mRNA was increased $(p<$ 0.05) compared with the vehicle and control groups (Fig. 3).

Doppler ultrasonography. The baseline ultrasonographic parameters did not differ between the groups. In the LPS group, $6 \mathrm{~h}$ after the injection, FHR and outflow $\mathrm{V}_{\text {mean }}$ were lower $(p<0.01)$, and ICT\% and IRT\% values were higher $(p$ $<0.001)$ than in the vehicle and control groups (Table 1). In the LPS group, the DAo and UA PI values were higher $(p<$ 0.01 ) than in the vehicle and control groups. However, the ICA PI values did not differ significantly between the groups. In venous circulation, PIV in IVC and DV were higher in the LPS group than in the vehicle and control groups. Doppler ultrasonographic parameters showed no significant differences between the vehicle and control groups six hours after the operation (Table 1).
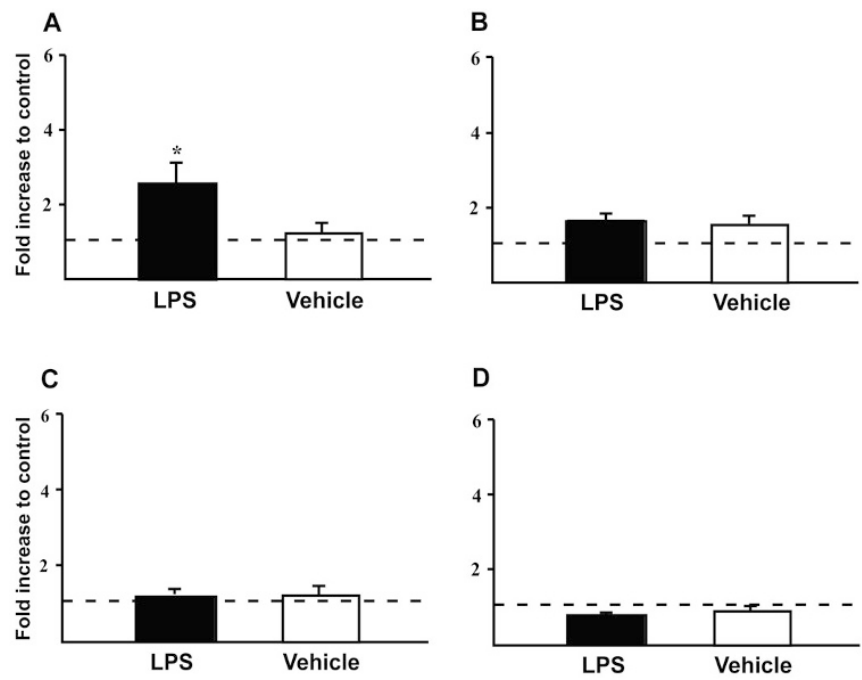

Figure 3. Ventricular BNP $(A)$ and ANP $(B)$ mRNA expressions and atrial BNP $(C)$ and ANP $(D)$ mRNA expressions. The data are expressed as a fold increase in mRNA levels in the LPS $(n=15)$ and vehicle $(n=14)$ groups relative to the control group $(n=6)$ (dotted line). Results are mean $\pm \mathrm{SE}, * p$ $<0.05$ vs control group.
Correlation of Doppler ultrasonographic parameters with ventricular BNP mRNA expression. A negative correlation $(R=0.56, p<0.005)$ was found between ventricular BNP mRNA expression and outflow $\mathrm{V}_{\text {mean }}$ (Fig. 4). Positive correlations were found between ventricular BNP mRNA expression and DAo PI $(R=0.56, p<0.005)$ and ICT\% $(R=0.62$, $p<0.001)$. In venous circulation, ventricular BNP mRNA expression correlated positively $(R=0.41, p<0.05)$ with IVC PIV (Fig. 4).

\section{DISCUSSION}

Based on our earlier findings, this study was designed to further explore the relationships between fetal myocardial inflammation, cardiovascular compromise, and cardiac natriuretic peptide expression after endotoxin-induced severe fetal cardiac dysfunction. Our in vivo fetal mouse model showed that ventricular BNP mRNA expression was significantly induced, whereas atrial and ventricular ANP and atrial BNP mRNA expressions were not activated after an LPS injection. These fetuses demonstrated similar signs of severe cardiovascular dysfunction that have been previously described in a mouse model of fetal inflammatory response (3). In contrast, direct stimulation with LPS significantly induced proinflammatory cytokine production without a detectable increase in natriuretic peptide expression in cultured fetal hearts.

An increase in workload initiates an adaptive process to maintain or even increase cardiac output (9). Increased transcription of the BNP gene and elevated BNP levels in the ventricles have been seen in experimental cardiac overload models (10). A chronic cardiac overload in humans also substantially increases the ventricular levels of BNP mRNA (11). Our results with the in vivo mouse model demonstrated that, in the fetal ventricle, BNP mRNA expression is increased in proportion to a rise in the ventricular afterload. This finding is in agreement with earlier studies revealing that wall stretch induces rapid activation of BNP gene expression within one hour in the left ventricle (12), whereas induction of ANP gene expression is seen within $1 \mathrm{~d}$ after the initiation of increased cardiac overload (13). Inflammation has been suggested to increase plasma concentrations of natriuretic peptides in adults with acute cardiac allograft rejection (14). In addition, Tomaru and co-workers (15)have shown LPS induced production of BNP in isolated neonatal cardiomyocytes in vitro. In in vitro organ culture, we found significant inductions of various proinflammatory mediators in fetal heart after LPS exposure, which confirms the findings made with our earlier in vivo model. However, no induction in the expression of natriuretic peptides was found in vitro, indicating that acute exposure to bacterial toxin does not directly influence the expression of the natriuretic peptides in the fetal heart.

In adult animal models, early myocardial dysfunction has been related to direct LPS effects and rapid LPS-stimulated production of proinflammatory cytokines $(16,17)$. Reduced function and contractile reserve occur within minutes to hours following LPS exposure (18). After the intra-amniotic LPS injection, the fetal cardiac outflow mean velocity, which is directly proportional to volume blood flow, was less than that 
Table 1. Doppler ultrasonographic parameters of fetal central and peripheral hemodynamics before and 6 h after injections

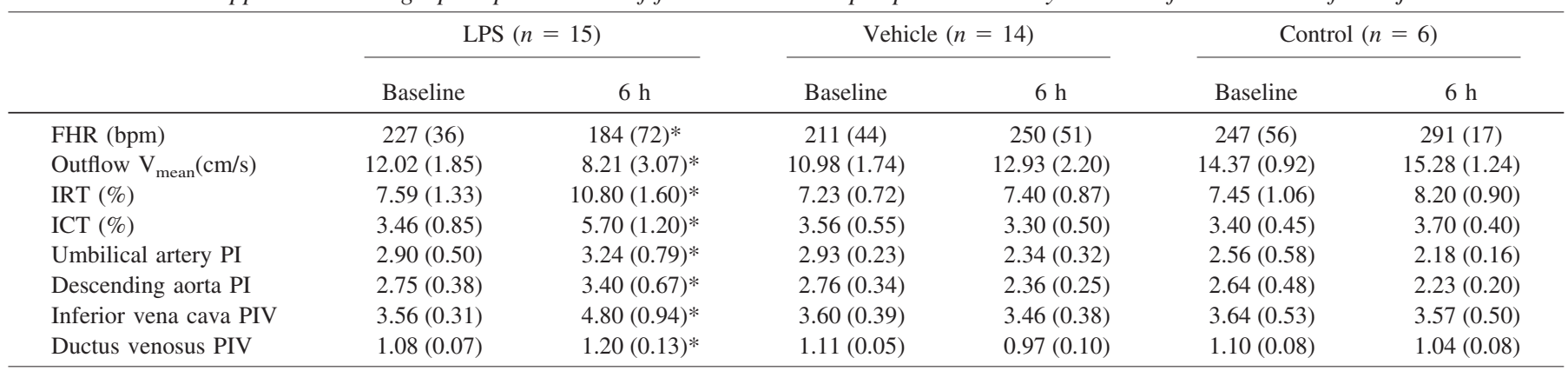

$\mathrm{V}_{\text {mean }}$, mean velocity; IRT and ICT, proportions (\%) of isovolumetric relaxation and contraction times of the cardiac cycle. All values given are means (SD). $* p<0.05$ vs vehicle and control groups.
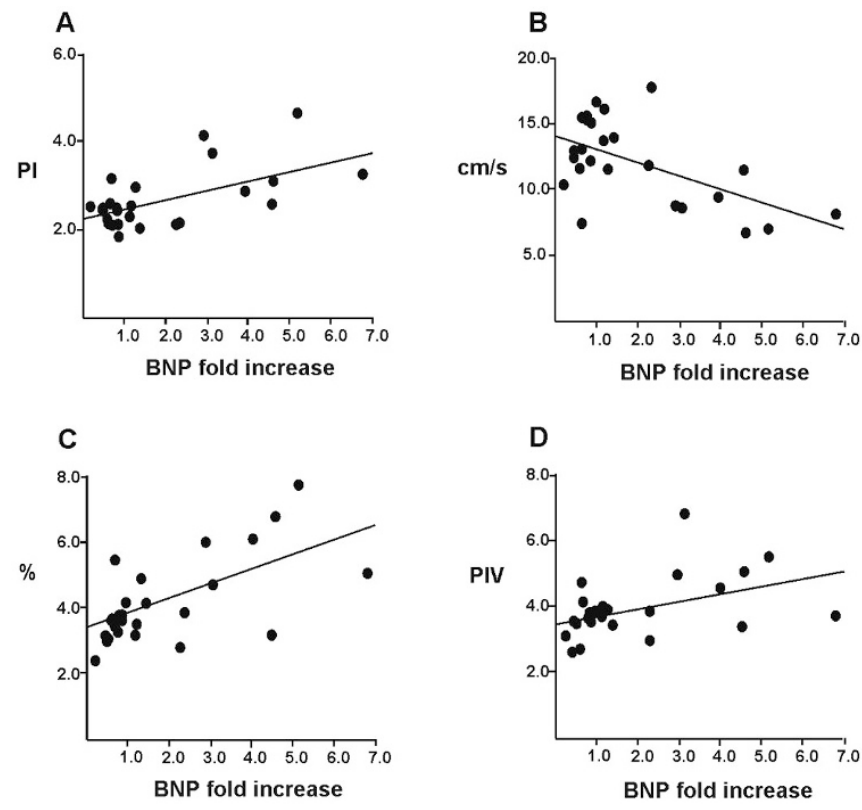

Figure 4. Fetal ventricular BNP mRNA expression and cardiovascular hemodynamics. Correlations between fetal ventricular BNP mRNA expression (fold increase relative to the control group) and $(A)$ descending aorta PI values $(\mathrm{y}=0.21 \mathrm{x}+2.30 ; R=0.56, p<0.005),(B)$ outflow mean velocity $\left(\mathrm{V}_{\text {mean }}\right)$ $(\mathrm{y}=-1.01 \mathrm{x}+14.04 ; R=0.56, p<0.005),(C)$ proportion $(\%)$ of isovolumetric contraction time of the cardiac cycle $(\mathrm{y}=0.47 \mathrm{x}+3.36 ; R=$ $0.62, p<0.001)$, and $(D)$ inferior vena cava PI values for veins $(\mathrm{y}=0.21 \mathrm{x}$ $+3.55 ; R=0.41, p<0.05)$. Total $n=25$

in the fetuses without LPS, indicating a drop in the fetal cardiac output. Again, there was a significant negative correlation between the level of ventricular BNP mRNA and the fetal cardiac outflow mean velocity. The fetuses with an intra-amniotic LPS injection had greater ICT\% and IRT\% than the other fetuses. The higher the ventricular expression of BNP, the greater was ICT\%. This shows that the pressure generation of the myocardium in the early part of systole as well as the myocardial relaxation in early diastole were impaired. In adults, BNP has been shown to be a sensitive marker of silent myocardial ischemia and a good predictor of heart failure (19). In the present mouse model of fetal inflammatory response, fetal cardiac compromise was characterized by a drop in cardiac output and abnormalities in the early phases of the myocardial contraction and relaxation processes.
In human fetuses with placental insufficiency and a rise in the umbilical artery N-terminal peptide of proANP concentrations, pulsatility in the systemic venous blood velocity waveforms was found to be increased compared with fetuses with normal umbilical artery concentrations of $\mathrm{N}$-terminal peptide of proANP (20). Thus, increased pulsatility in the systemic venous blood velocity waveforms reflects a rise in systemic venous pressure (21). In the present study, a rise in ventricular BNP mRNA was related to increased PIV values in DV and IVC. This finding demonstrates that increased pulsatility in the systemic venous blood velocity waveforms is associated with fetal cardiac compromise.

Atrial and ventricular ANP gene expressions were not acutely induced following LPS. Previous fetal studies have shown that ventricular ANP is released in response to a rise in fetal cardiac afterload $(22,23)$. It is possible that ventricular ANP production is activated after longer ventricular exposure to increased afterload. The atria and fetal ventricles contain large quantities of stored proANP (24). Thus, in principle, substantial amounts of ANP could be released from the heart without a need for increased transcription of the ANP gene or increased synthesis of proANP. The ANP mRNA levels may therefore not directly reflect the amount of circulating biologic activity of ANP. On the other hand, the cardiac levels of BNP mRNA and the circulating biologic activity of BNP are more closely linked because the cardiac stores of BNP are small and the secretion of BNP is dependent on constant synthesis (25). Furthermore, plasma BNP levels have been reported to increase to a greater degree than ANP levels in patients with congestive heart failure (26). The finding of increased ventricular BNP production with no significant increase in ANP secretion is thus in accordance with the previous findings.

Due to the small cardiac size of the fetal mouse, it is impossible to distinguish between right and left ventricular inflow and outflow areas with this ultrasound imaging technique. However, fetal circulation is characterized by open ductus arteriosus and foramen ovale. Fetal ventricles therefore function in parallel and the pressure faced by both ventricles is equal. The pathophysiological effects could thus be expected to be similar in both ventricles. Our previous study on fetal mice demonstrated good reproducibility of the Doppler parameters, thus validating this methodology (3). Similar results concerning reproducibility have also been reported previously in human and animal studies $(6,27)$. 
In conclusion, in response to LPS, in vitro cultured fetal hearts showed increased production of proinflammatory cytokines, whereas cardiac natriuretic peptide expression levels remained unaffected. This suggests that the acute inflammation caused by bacterial endotoxin does not significantly induce cardiac natriuretic peptide expressions in the fetus. Our in vivo model showed acute fetal cardiac dysfunction after intra-amniotic LPS, which was related to an increase in ventricular BNP mRNA expression. A rise in fetal ventricular BNP mRNA expression was associated with an increase in fetal cardiac afterload, a drop in fetal cardiac output, abnormalities in the early phases of myocardial relaxation and contraction periods, and a rise in the pulsatility of the systemic venous blood velocity waveforms. Thus, ventricular BNP gene expression was increased in proportion to the severity of the fetal hemodynamic compromise.

\section{REFERENCES}

1. Romero R, Espinoza J, Goncalves L, Gomez R, Medina L, Silva M, Chaiworapongsa T, Yoon BH, Ghezzi F, Lee W, Treadwell M, Berry SM, Maymon E, Mazor M, Devore G 2004 Fetal cardiac dysfunction in preterm premature rupture of membranes. J Matern Fetal Neonatal Med 16:146-157

2. Yanowitz TD, Jordan JA, Gilmour CH, Towbin R, Bowen A, Roberts JM, Brozanski BS 2002 Hemodynamic disturbances in premature infants born after chorioamnionitis: association with cord blood cytokine concentrations. Pediatr Res 51:310-316

3. Rounioja S, Rasanen J, Glumoff V, Ojaniemi M, Makikallio K, Hallman M 2003 Intra-amniotic lipopolysaccharide leads to fetal cardiac dysfunction. A mouse model for fetal inflammatory response. Cardiovasc Res 60:156-164

4. Sagnella GA 1998 Measurement and significance of circulating natriuretic peptides in cardiovascular disease. Clin Sci (Lond) 95:519-529

5. Cameron VA, Ellmers LJ 2003 Minireview: natriuretic peptides during development of the fetal heart and circulation. Endocrinology 144:2191-2194

6. Gui YH, Linask KK, Khowsathit P, Huhta JC 1996 Doppler echocardiography of normal and abnormal embryonic mouse heart. Pediatr Res 40:633-642

7. Maki JM, Rasanen J, Tikkanen H, Sormunen R, Makikallio K, Kivirikko KI, Soininen R 2002 Inactivation of the lysyl oxidase gene Lox leads to aortic aneurysms, cardiovascular dysfunction, and perinatal death in mice. Circulation 106:2503-2509

8. Majalahti-Palviainen T, Hirvinen M, Tervonen V, Ilves M, Ruskoaho H, Vuolteenaho O 2000 Gene structure of a new cardiac peptide hormone: a model for heart-specific gene expression. Endocrinology 141:731-740

9. Tokola H, Hautala N, Marttila M, Magga J, Pikkarainen S, Kerkela R, Vuolteenaho O, Ruskoaho H 2001 Mechanical load-induced alterations in B-type natriuretic peptide gene expression. Can J Physiol Pharmacol 79:646-653
10. Dagnino L, Drouin J, Nemer M 1991 Differential expression of natriuretic peptide genes in cardiac and extracardiac tissues. Mol Endocrinol 5:1292-1300

11. Hosoda K, Nakao K, Mukoyama M, Saito Y, Jougasaki M, Shirakami G, Suga S, Ogawa Y, Yasue H, Imura H 1991 Expression of brain natriuretic peptide gene in human heart. Production in the ventricle. Hypertension 17:1152-1155

12. Magga J, Vuolteenaho O, Tokola H, Marttila M, Ruskoaho H 1998 B-type natriuretic peptide: a myocyte-specific marker for characterizing load-induced alterations in cardiac gene expression. Ann Med 30 (suppl 1):39-45

13. Ruskoaho H 1992 Atrial natriuretic peptide: synthesis, release, and metabolism Pharmacol Rev 44:479-602

14. Masters RG, Davies RA, Veinot JP, Hendry PJ, Smith SJ, de Bold AJ 1999 Discoordinate modulation of natriuretic peptides during acute cardiac allograft rejection in humans. Circulation 100:287-291

15. Tomaru Ki K, Arai M, Yokoyama T, Aihara Y, Sekiguchi Ki K, Tanaka T, Nagai R, Kurabayashi M 2002 Transcriptional activation of the BNP gene by lipopolysaccharide is mediated through GATA elements in neonatal rat cardiac myocytes. J Mol Cell Cardiol 34:649-659

16. Yasuda S, Lew WY 1997 Lipopolysaccharide depresses cardiac contractility and beta-adrenergic contractile response by decreasing myofilament response to $\mathrm{Ca} 2+$ in cardiac myocytes. Circ Res 81:1011-1020

17. Kapadia S, Lee J, Torre-Amione G, Birdsall HH, Ma TS, Mann DL 1995 Tumor necrosis factor-alpha gene and protein expression in adult feline myocardium after endotoxin administration. J Clin Invest 96:1042-1052

18. Takeuchi K, del Nido PJ, Ibrahim AE, Poutias DN, Glynn P, Cao-Danh H, Cowan DB, McGowan Jr FX 1999 Increased myocardial calcium cycling and reduced myofilament calcium sensitivity in early endotoxemia. Surgery 126:231-238

19. de Lemos JA, Morrow DA, Bentley JH, Omland T, Sabatine MS, McCabe CH, Hall C, Cannon CP, Braunwald E 2001 The prognostic value of B-type natriuretic peptide in patients with acute coronary syndromes. N Engl J Med 345:1014-1021

20. Makikallio K, Vuolteenaho O, Jouppila P, Rasanen J 2002 Ultrasonographic and biochemical markers of human fetal cardiac dysfunction in placental insufficiency. Circulation 105:2058-2063

21. Gudmundsson S, Gunnarsson GO, Hokegard KH, Ingemarsson J, Kjellmer I 1999 Venous Doppler velocimetry in relationship to central venous pressure and heart rate during hypoxia in the ovine fetus. J Perinat Med 27:81-90

22. Walther T, Stepan H, Faber R 2001 Dual natriuretic peptide response to volume load in the fetal circulation. Cardiovasc Res 49:817-819

23. Ville Y, Proudler A, Abbas A, Nicolaides K 1994 Atrial natriuretic factor concentration in normal, growth-retarded, anemic, and hydropic fetuses. Am J Obstet Gynecol 171:777-783

24. de Bold AJ, Bruneau BG, Kuroski de Bold ML 1996 Mechanical and neuroendocrine regulation of the endocrine heart. Cardiovasc Res 31:7-18

25. Magga J, Vuolteenaho O, Tokola H, Marttila M, Ruskoaho H 1997 Involvement of transcriptional and posttranscriptional mechanisms in cardiac overload-induced increase of B-type natriuretic peptide gene expression. Circ Res 81:694-702

26. Mukoyama M, Nakao K, Hosoda K, Suga S, Saito Y, Ogawa Y, Shirakami G, Jougasaki M, Obata K, Yasue H, Kambayashi Y, Inouye K, Imamura H 1991 Brain natriuretic peptide as a novel cardiac hormone in humans. Evidence for an exquisite dual natriuretic peptide system, atrial natriuretic peptide and brain natriuretic peptide. J Clin Invest 87:1402-1412

27. Tei C 1995 New non-invasive index for combined systolic and diastolic ventricular function. J Cardiol 26:135-136 